\title{
STRUCTURE AND COMPOSITION OF EDAPHIC ARTHROPOD COMMUNITY AND ITS USE AS BIOINDICATORS OF ENVIRONMENTAL DISTURBANCE
}

\author{
Beiroz, W. ${ }^{1}$ - AudinO, L. D. ${ }^{2}$ - QueIroz, A. C. M. ${ }^{1}-$ RABELlo, A. M. ${ }^{1}$ - Boratto, I. A. ${ }^{1}-$ \\ SILVA, $Z^{3}$. - RIBAS, C. R. ${ }^{1 *}$ \\ ${ }^{1}$ Departamento de Biologia, Setor de Ecologia, Universidade Federal de Lavras, Campus \\ Universitário, Caixa Postal 3037, 37200-000 - Lavras, Minas Gerais, Brazil. \\ (phone: +55-35-3829-1924) \\ ${ }^{2}$ Departamento de Entomologia, Universidade Federal de Lavras, Campus Universitário, \\ Caixa Postal 3037, 37200-000 - Lavras, Minas Gerais, Brazil. \\ (phone: +55-35-3829-5128) \\ ${ }^{3}$ Naturali Consultoria Ambiental, \\ Lavras, Minas Gerais, Brazil. \\ (phone: +55-35-3821-5108) \\ *Corresponding author \\ e-mail:crribas@gmail.com \\ (Received $2^{\text {nd }}$ Dec $2013 ;$ accepted $22^{\text {nd }}$ July 2014)
}

\begin{abstract}
We analyzed arthropod community structure and composition among different anthropogenic systems. The study was conducted in areas of secondary forest (control system), Eucalyptus plantation and pasture, where we sampled arthropods using pitfall traps. The systems did not differ in mean richness and mean abundance of arthropods, however, eucalyptus presented the highest total richness. The systems supported different arthropod communities in relation to structure and species composition. Pasture was the most simplified and different system in comparison to the others, probably because it is more open and presents low complexity. Our results demonstrate that different anthropogenic systems exhibit communities that reflect its characteristics, corroborating the evidence that human impacts are capable of changing community composition and structure. Our study serves to understand arthropod response in face of environmental disturbance, selecting indicator morphospecies and orders of arthropods for different anthropogenic systems and providing valid information for the development of conservation strategies.
\end{abstract}

Keywords: Atlantic Forest, Eucalyptus, Habitat change, Pasture, Vegetation complexity

\section{Introduction}

The introduction of different anthropogenic systems in natural ecosystems can reduce biodiversity and alter the functioning of these environments (Chapin et al., 2000; Sala et al., 2000). Biodiversity loss occurs by the simplification of complex and diversified ecosystems, since environments with high habitat heterogeneity present higher species diversity (Pianka, 1983). Therefore, the evaluation of biological communities is essential, due to the growing need to maintain ecological integrity of natural and anthropogenic systems (Basset et al., 2008).

In this context, soil arthropods have been widely used as bioindicator organisms in order to quantify and qualify the conditions of an environment (e.g. Dufrêne and Legendre 1997; Maleque et al., 2009; Almeida et al., 2011; Gerlach et al., 2013). Soil arthropods are considered good bioindicators because of their high diversity, easy and 
low sampling cost, wide spatial and temporal distribution, rapid response to environmental changes and participation in several ecological processes of ecosystems maintenance (Lavelle, 1996; Knoepp et al., 2000; Nakamura et al., 2007). The bioindication of these organisms enables to infer about an ecosystem condition, providing scientific basis for environmental management and conservationist strategies (Suthar, 2009; Gerlach et al., 2013).

Several studies have used the diversity of a single taxon as a bioindicator, however the evaluation of different taxonomic groups is necessary (Schulze et al., 2004), because each taxon can present a specific response to environmental modifications. Studies that use various taxa allows to reach more concrete conclusions, as well as to reduce the costs that are involved in the execution of a scientific project (Barlow et al., 2007; Gardner et al., 2008).

This work aimed to evaluate the structure and composition of soil arthropod communities in areas of secondary forest, Eucalyptus plantation and pasture and also to identify possible indicators of each system. We tested the hypothesis that arthropod fauna will respond negatively to the decrease of system complexity, reducing their abundance, species richness and evenness, and increasing their dominance patterns. We also expect that each anthropogenic system will sustain distinct arthropods communities according to structure and species composition and that they will possess specific indicators.

\section{Material and methods}

\section{Study sites}

The study was conducted at the Universidade Federal de Lavras, in areas of secondary forest, Eucalyptus plantations and pastures. The municipality of Lavras is

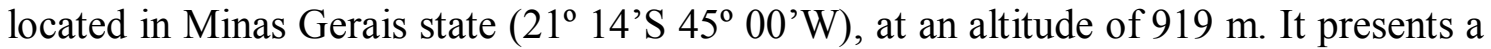
mesothermal climate (Cwa), according to Köppen classification, with a dry winter and rainy summer, average annual temperature of $20.4{ }^{\circ} \mathrm{C}$ and a rainfall of $1460 \mathrm{~mm}$ (Dantas et al., 2007).

The landscape of our study site is composed by Atlantic Forest remnants surrounded by an agro-silvo-pastoral matrix of agricultural crops, pastures and monocultures such as Eucalyptus plantations (Oliveira-Filho et al., 1994). Most of the forests are secondary formations in different successional stages with less than 10 ha (Oliveira-Filho et al., 1994). Therefore, this area provides excellent conditions to generate information on how the edaphic arthropod community responds to different agro-silvo-pastoral land use systems.

\section{Arthropods sampling}

The present work was carried out in April 2011, when we sampled three areas (replicates) of each anthropogenic system: secondary forest, Eucalyptus plantation and pasture. Secondary forest was considered the control system in order to understand the consequences of habitat change for edaphic arthropods.

We sampled edaphic arthropods using pitfall traps without baits. A transect of $80 \mathrm{~m}$ was delimited at each anthropogenic system, at least $20 \mathrm{~m}$ distant from the edges. At every $20 \mathrm{~m}$ of the transect we placed a pitfall trap, corresponding to a total of 5 traps per 
area, totalizing 15 pitfalls per anthropogenic system. Pitfall traps were left in the field for 24 hours.

We identified arthropods at family level whenever possible and specimens were grouped in morphospecies. Specimen's identification was based on Borror et al. (1989).

\section{Data analysis}

We generated a species accumulation curves according to the number of samples to evaluate sampling effort and to compare the patterns of total species richness among the studied anthropogenic systems. This analysis was performed in EstimateS 7.5.2 (Colwell, 2005).

To verify if arthropods' mean abundance and mean species richness (response variables) are different among the different anthropogenic systems (explanatory variables), we used generalized linear models (GLM) with Gaussian error distribution. All models were submitted to residual analysis to verify their suitability to error distribution. These analyses were conducted in the $\mathrm{R}$ ( $\mathrm{R}$ Development Core Team, 2012).

In order to observe dominance patterns in arthropod community of each anthropogenic system, we constructed abundance distribution curves. Abundance data was $(\log +1)$ transformed. We also calculated the evenness of each anthropogenic system through the software Species Diversity and Richness 3.0. Evenness values were statistically compared using the null model approach developed by Solow (1993).

To evaluate if there were significant differences in community structure (abundance) and composition (presence/absence) we performed an analysis of similarity (ANOSIM). Bray-Curtis index was used as a similarity measure for the abundance data and RaupCrick index for species composition (presence/absence). The analysis was carried out using software R (R Development Core Team, 2012), package Vegan (Oksanen et al., 2013).

In order to identify morphoespecies and orders of arthropods that are indicators for each anthropogenic system, we conducted an IndVal analysis (Indicator Species Analyses), using software R, package labdsv (R Development Core Team, 2012 Roberts, 2013).

\section{Results}

We collected 981 arthropods of 92 morphospecies distributed in 14 taxonomic groups: Acari, Aranae, Blattodea, Coleoptera, Diptera, Embioptera, Formicidae, Hemiptera, Hymenoptera, Isopoda, Isoptera, Orthoptera, Trichoptera and Thysanoptera.

Species accumulation curves did not reach an asymptote in any of the studied systems (Fig. 1). These curves also showed that total richness of forest and pasture was not different between each other and Eucalyptus exhibited the highest total richness.

We captured 45 morphospecies and 267 individuals in Eucalyptus; 36 morphospecies and 261 individuals in the forest and 35 morphospecies and 451 individuals in the pasture. However, these anthropogenic systems did not differ in relation to the mean number of arthropod morphospecies $\left(\mathrm{F}_{2,15}=2.02 ; \mathrm{p}=0.21\right)$ and mean abundance $\left(\mathrm{F}_{2,15}\right.$ $=0.61 ; \mathrm{p}=0.58$ ).

Forest and the Eucalyptus presented similar evenness indexes $(\mathrm{p}=0.75), 0.56$ and 0.58 , respectively. Pasture showed the smallest evenness index (0.48), differing from the forest $(\mathrm{p}<0.001)$ and Eucalyptus $(\mathrm{p}<0.001)$. 
The systems presented similar abundance distribution curves, where some species showed numeric dominance over the other relatively less abundant (Fig. 3). In all the systems, the four morphospecies with higher abundance were representatives of the family Formicidae, except for the Diptera sp. 1, which was the fourth most abundant of the forest (Fig. 2). However, the species that dominate each anthropogenic system is different.

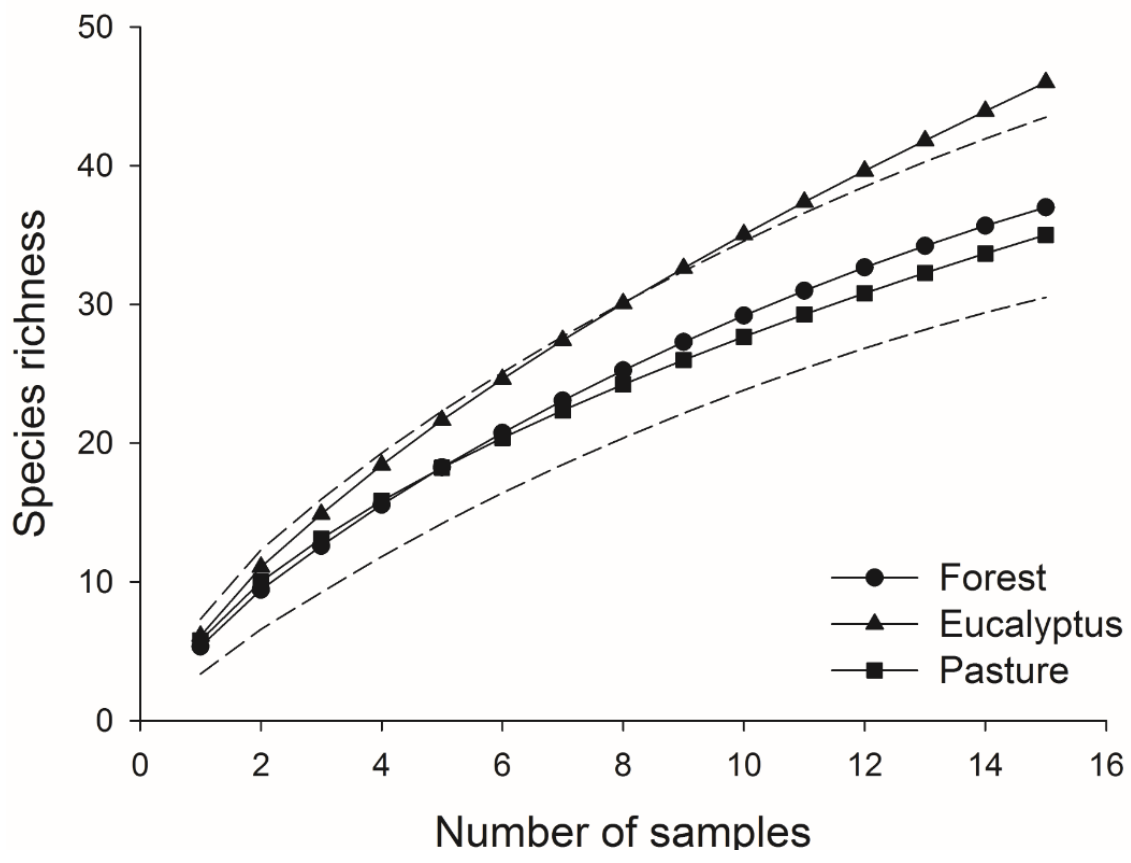

Figure 1. Species accumulation curve of soil arthropods sampled in forest, Eucalyptus and pasture areas located at Lavras, state of Minas Gerais, Brazil. Dashed lines represent the confidence interval (95\%) of the forest.

The anthropogenic systems exhibited different arthropod community structures and compositions (Table 1). Of the 92 collected morphospecies, only seven were common to all of the systems, and these include one Diptera species and six of ants. Forest and Eucalyptus plantation shared 8 species between each other, while forest and pasture just presented one species in common and Eucalyptus plantation and pasture just one species in common too. Eucalyptus presented the highest number of exclusive species (29 morphospecies - 64.4\% exclusive species), followed by the pasture (26 morphospecies - 74\%) and forest (20 morphospecies - 55\%).

Only one species was indicator of the forest (Diptera sp. 1). Two species were considered indicators of the Eucalyptus (Diptera sp. 4 and Isopoda sp. 1). In the pasture, there were three indicator species: Acridiidae sp. 2, Formicidae sp. 3 and Formicidae sp. 6 (Table 2). Considering a higher taxonomic level (arthropods order) forest did not show any indicators, while Eucalyptus showed two (Isopoda and Diptera) and pasture two indicator groups (Hemiptera and Orthoptera) (Table 3). 


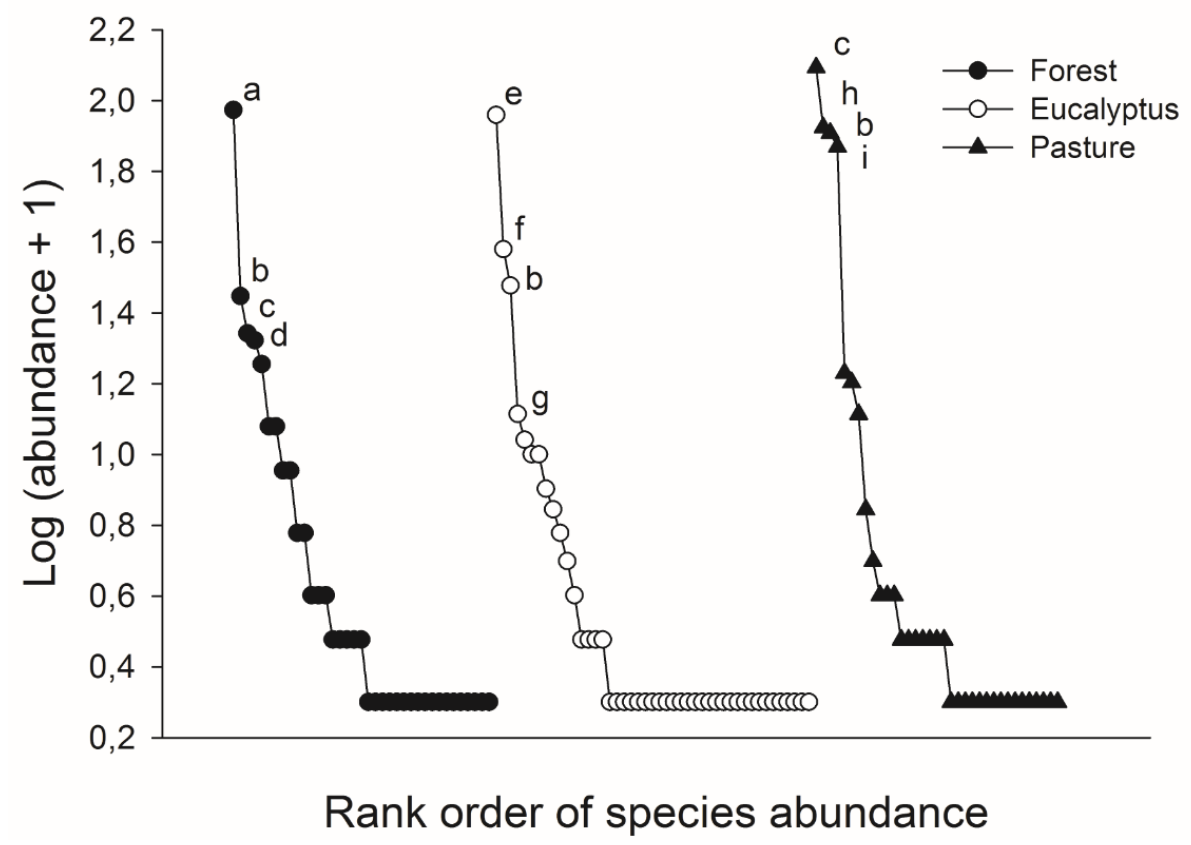

Figure 2. Rank abundance distribution of arthropod species sampled in three different landscape uses (Forest, Eucalyptus plantation and Pasture) of south Minas Gerais, Lavras, Brazil. a) Formicidae sp. 13; b) Formicidae sp. 5; c) Formicidae sp. 8; d) Diptera sp. 1; e) Formicidae sp. 1; f) Formicidae sp. 12; g) Formicidae sp. 4; h) Formicidae sp. 3; i) Formicidae sp. 6.

Table 1. $R$ and $p$ values from the similarity analysis (ANOSIM) implemented to evaluate possible differences in arthropods community structure (abundance) and community species composition (presencelabsence) between the forest, Eucalyptus and pasture areas (Lavras, Minas Gerais, Brazil). Levels significance $p \leq 0.05, p \leq 0.01$ and $p \leq 0.001$ are represented by $*, * *, * * *$ respectively.

\begin{tabular}{l|c|c|c|c}
\hline \multirow{2}{*}{ Systems } & \multicolumn{2}{c|}{ Community structure } & \multicolumn{2}{c}{ Community composition } \\
\cline { 2 - 5 } & $\mathbf{R}$ & $\mathbf{P}$ & $\mathbf{R}$ & $\mathbf{P}$ \\
\hline Forest x Eucalyptus & 0.13 & $0.005^{* *}$ & 0.2 & $0.0005^{* * *}$ \\
Forest x Pasture & 0.25 & $<0.001^{* * *}$ & 0.44 & $<0.001^{* * *}$ \\
Eucalyptus x Pasture & 0.27 & $<0.001^{* * *}$ & 0.38 & $<0.001^{* * *}$ \\
\hline
\end{tabular}

In relation to the number of different arthropod orders captured in each anthropogenic system, forest exhibited 12, Eucalyptus 11 and pasture eight (Fig. 3). The species richness and the abundance of individuals of each taxonomic group were different among the systems. Of the 14 groups, only five were common to all systems (Aranae, Diptera, Coleoptera, Formicidae and Hymenoptera). Two groups were exclusive to the forest (Embioptera and Trichoptera) and none was exclusive to 
Eucalyptus and pasture and these last systems shared two groups, Acari and Hemiptera (Fig. 3).
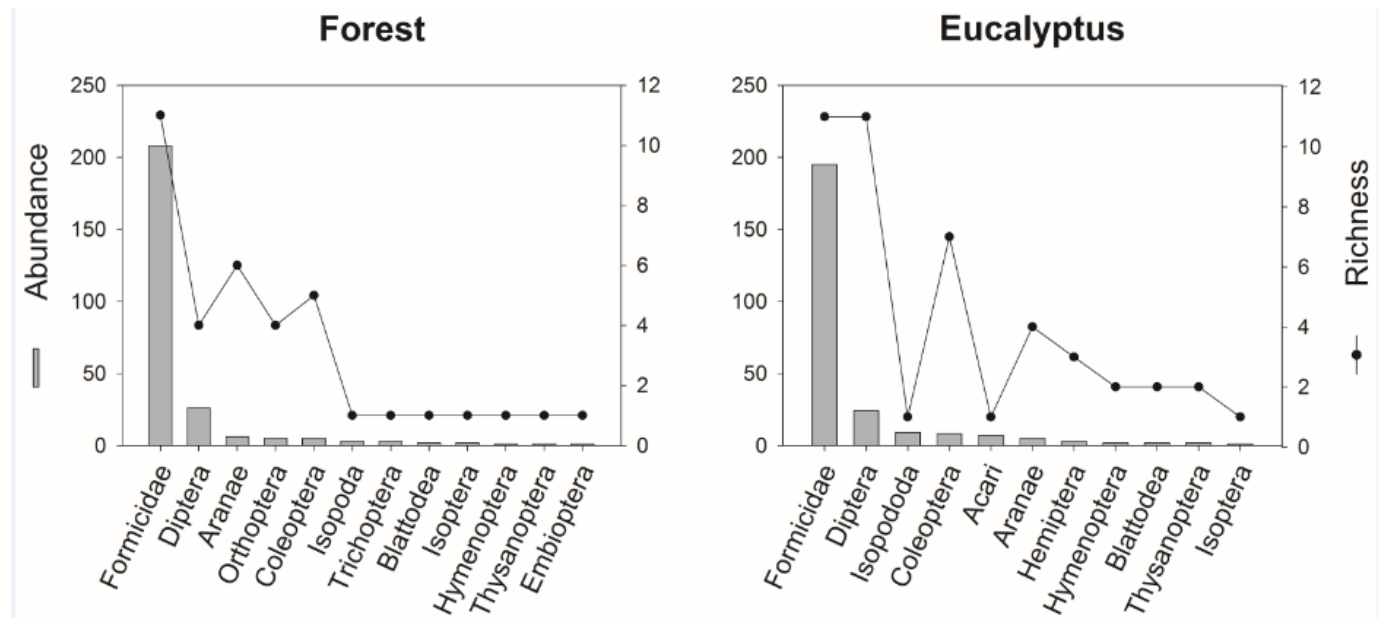

Pasture

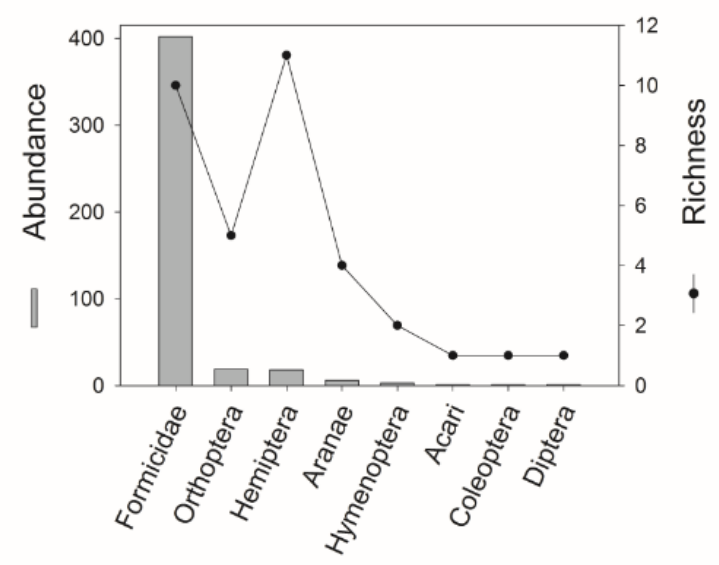

Figure 3. Abundance and species richness of the taxonomic groups sampled in forest areas, eucalyptus plantations and pastures of south Minas Gerais, Lavras, Brazil.

Table 2. Arthropod morphospecies with significant values of IndVal $(p<0.05)$ sensitive to the different anthropogenic systems (Forest, Eucalyptus and Pasture) inserted in the municipality of Lavras, state of Minas Gerais, Brazil. IV: indication value. Significance levels: $p \leq 0.05, p \leq 0.01$ and $p \leq 0.001$ are represented by $*, * *, * * *$ respectively.

\begin{tabular}{c|c|c|c}
\hline Morphospecies & Systems & IV & P \\
\hline Diptera sp. 1 & Forest & 56.4 & $0.0004^{* * *}$ \\
Diptera sp. 4 & Eucalyptus & 48 & $0.0006^{* * *}$ \\
Isopoda sp. 1 & Eucalyptus & 30 & $0.02^{*}$ \\
Acrididae sp. 2 & Pasture & 53.3 & $0.0002^{* * *}$ \\
Formicidae sp. 3 & Pasture & 32.2 & $0.02 *$ \\
Formicidae sp. 6 & Pasture & 57.3 & $0.001^{* * *}$ \\
\hline
\end{tabular}


Table 3. Arthropod orders with significant values of IndVal $(p<0.05)$ sensitive to the different anthropogenic systems (Forest, Eucalyptus and Pasture) inserted in the municipality of Lavras, state of Minas Gerais, Brazil. IV: indication value. Significance levels: $p \leq 0.05, p \leq 0.01$ and $p \leq 0.001$ are represented by $*, * *, * * *$ respectively.

\begin{tabular}{c|c|c|c}
\hline Arthropod orders & System & IV & P \\
\hline Isopoda & Eucalyptus & 30 & $0.02^{*}$ \\
Diptera & Eucalyptus & 40.8 & $0.04^{*}$ \\
Hemiptera & Pasture & 51.4 & $0.0008^{* * *}$ \\
Orthoptera & Pasture & 52.8 & $0.0008^{* * *}$ \\
\hline
\end{tabular}

\section{Discussion}

Several studies have already shown that arthropod diversity is highly affected by the modification of natural ecosystems and implantation of different anthropogenic uses (e.g. Basset et al., 1998; Lawton, 1999; Schulze et al., 2004; Basset et al., 2008), due to the changes in vegetation structure (e.g. Siemann et al., 1998; Wettstein and Schmid, 1999; Gardner et al., 2008).

Natural environments tend to sustain higher arthropod diversity because of their higher spatial heterogeneity, since they possess more species richness of trees and an understory usually developed (Elton, 1973). This complex vegetation structure creates a larger amount of micro-habitats and more resources availability for the arthropods (Ribas et al., 2003; Tews et al., 2004). However, our results do not corroborate with these theoretical expectations, because mean arthropod richness and abundance did not differ among the systems, despite having extreme differences in vegetation structure. Likewise Eucalyptus total richness was higher than the observed in the forest.

However, these two parameters of the arthropod community (richness and abundance) by themselves cannot reflect the reality of the studied systems, as confirmed by several studies (e.g. Hoffmann, 2010; Gollan et al., 2011; Ribas et al., 2012). Furthermore, Fleishman et al. (2006) reported that richness is not an appropriate metric for conservation planning strategies, because do not provide information about the identity of species. Abundance also cannot be considered a good indicator of habitat quality, since several species increase their populations in face of a disturbance (Hillebrand et al., 2008; Blaum et al., 2009), altering dominance structure in the community (Vasconcelos, 1999; Loyola et al., 2006). Thus, Barlow et al. (2007) recommended that to obtain more robust responses about how biological communities resist to disturbances, the use of metrics based on the similarity among communities is more reliable.

Our results showed that forest, Eucalyptus and pasture sustained highly dissimilar arthropod communities both in structure and species composition. Loyola et al. (2006) found this same pattern when studying the invertebrate community in areas of forest and pasture in Pantanal wetlands, while Ferreira and Marques (1998) verified low similarity between litter arthropod communities of secondary forest and Eucalyptus monoculture, as well as, arthropod richness and diversity of secondary forest and Eucalyptus monoculture. All these results, therefore, corroborate with the evidences, that 
modifications of natural ecosystems caused by human activities generate changes in composition and structure of biological communities (Hillebrand et al., 2008).

Pasture showed a simplified arthropod community, because of its lowest evenness, number of taxonomic groups and absence of exclusive arthropod orders. According to Hillebrand et al. (2008) alteration of ecosystems by humans is capable of strongly affect community evenness, being this metric very important to understand the response of the organisms to anthropic impacts. Low evenness can influence the interaction of species in a community, ecological processes and community resistance and resilience, because of the dominance of few species that are more resistant to the loss of vegetation covering (Hillebrand et al., 2008; Sobek et al., 2009). Thus, the lowest evenness found in the pasture is an indication of how much this system presents a more altered biological community in relation to the forested systems. Furthermore, among the landscape studied, pasture presented the most distinct community of arthropods, since $74 \%$ of the species found in this environment were exclusive to it, leading to a low number of species shared with the forest and Eucalyptus.

The substitution of forest areas by pastures represents an abrupt change in the environment, since removal of forest cover leads to a decrease in the amount of soil organic matter, the occurrence of erosive processes, higher soil compaction, litter loss and microclimatic alterations (Gash and Nobre, 1996; Alves et al., 1999; Mathieu et al., 2005; Loyola et al., 2006; Bernarde and Macedo, 2008). All these factors can be unfavorable for the survival of some species, mainly for those associated with forest environments (Howden and Nealis, 1975; Larsen et al., 2008). Thus, pasture does not maintain the same conditions of forest system in order to allow the establishment of similar fauna. Therefore, species found in pasture are in general those common of opened environments or habitat generalists. Following the changes in ant assemblages in different stages of vegetational succession, from cultivated fields up to forest environments, Gómez et al. (2003) found major changes including the increase of cryptics species and cold-climate specialists. They also reported a decrease of opportunists species as well the hot-climate specialists, followed by a decrease in ant species richness.

Forest and Eucalyptus were different in relation to arthropod species composition, probably as a reflection of the structural differences of these vegetational formations. Eucalyptus plantation consists of an environment with a single plant species and individuals with similar ages, besides the absence of an understory, promoting a discontinuous canopy cover favorable to a greater incidence of light. In this context, they are less complex environments when compared with the primary forest areas.

All anthropogenic systems exhibited indicator species, however, in relation to arthropod orders, just the Eucalyptus and pasture showed it. Most of these species and orders entered in the category of detectors, according to McGeoch et al. (2002) and Verdú et al. (2011), because they had an indication value between $45 \%$ and $70 \%$. Detector species just reflect preferences for a certain habitat type, but these species can also be found in adjacent systems, mainly when their habitat conditions are under change. None of our species presented an indication value above $70 \%$, which according to the above mentioned authors, is what characterizes real habitat indicators. In this study the forest, although being the most complex system, presented the lowest number of indicator species, it did not have indicator arthropod orders and sustained the lowest number of exclusive species. This might have occurred due to the degree of degradation and small size of the secondary forest fragments, which may not present the conditions 
inherent to more intact forest environments and may not represent the reality of wellpreserved forests. Nevertheless, it was the system with higher number of exclusive arthropods orders.

In conclusion, human activities change the composition and the structure of biological communities. Our results enable us to know the response of the arthropod community facing the implantation of different anthropogenic systems, selecting indicator species and orders of each system, which currently dominates the scenario of the south of Minas Gerais. The selection of bioindicators is of unquestionable importance, since with this information it is possible to choose and evaluate sites for the establishment of nature reserves, to create conservation management plans and to evaluate the ecological impacts generated by human activities. Such studies enable us to understand the processes that govern the disassembly of biological communities and to elaborate conservation strategies to minimize the impacts upon biodiversity.

Acknowledgments. We thank Universidade Federal de Lavras for the logistic support. F. M. França and V. R. Yoshino for the help in the field work. The authors receive financial support from CAPES (Coordenação de Aperfeiçoamento de Pessoal de Nível Superior) through postgraduate grants. This work was partially realized during subject PEC 519 - Evaluation and Environmental Monitoring with the use of bioindicator.

\section{REFERENCES}

[1] Almeida, S., Louzada, J., Sperber, C., Barlow, J. (2011): Subtle land-use change and tropical biodiversity: Dung beetle communities in Cerrado grasslands and exotic pastures. - Biotropica 43(6):704-710.

[2] Alves, F.S.M., Fisch, G., Vendrame, I.F. (1999): Modificações do microclima regime hidrológico devido ao desmatamento na Amazônia: estudo de um caso em Rondônia (RO), Brasil. - Acta Amazônica 29(3):395-409.

[3] Barlow, J., Overal, W.L., Araujo, I.S., Gardner, T.A., Peres, C.A. (2007): The value of primary, secondary and plantation forests for fruit-feeding butterflies in the Brazilian Amazon. - Journal of Applied Ecology 44(27):1001-1012.

[4] Basset, Y., Missa, O., Alonso, A., Miller, S.E., Curletti, G., De Meyer, M., Eardley, C., Lewis, O.T., Mansell, M.W., Novotny, V., Wagner, T. (2008): Changes in arthropod assemblages along a wide gradient of disturbance in Gabon. - Conservation Biology 22(6):1552-1563.

[5] Basset, Y., Novotny, V., Miller, S.E., Springate, N.D. (1998): Assessing the impact of forest disturbance on tropical invertebrates: some comments. - Journal of Applied Ecology 35:461-466.

[6] Bernarde, P.S., Macedo, L.C. (2008): Impacto do desmatamento e formação de pastagens sobre a anurofauna de serapilheira em Rondônia. - Iheringia, Série Zoologia 98(4):454459 .

[7] Blaum, N., Seymour, C., Rossmanith, E., Schwager, M., Jeltsch, F. (2009): Changes in arthropod diversity along a land use driven gradient of shrub cover in savanna rangelands: identification of suitable indicators. - Biodiversity and Conservation 18:1187-1199.

[8] Borror, D.J., Triplehorn, C.A., Johnson, N.F. (1989): An introduction to the study of insects. - Saunders College Publisher: Philadelfia.

[9] Chapin, F.S., Zavaleta, E.S., Eviner, V.T., Naylor, R.L., Vitousek, P.M., Reynolds, H.L., Hooper, D.U., Lavorel, S., Sala, O.E., Hobbie, S.E., et al. (2000): Consequences of changing biodiversity. - Nature. 405:234-242. 
[10] Colwell, R.K. (2005): EstimateS: Statistical estimation of species richness and shared species from samples. - Version 8.0. [cited 2012 Feb 20]. Available from http://purl.oclc.org/estimates

[11] Dantas, A.A.A, Carvalho, L.G., Ferreira, E. (2007): Classificação e tendências climáticas em Lavras, MG. - Ciencia e Agrotecnologia 31(6):1862-1866.

[12] Dufrêne, M., Legendre, P. (1997): Species assemblages and indicator species: the need for a flexible asymmetrical approach. - Ecological Monographs 67(3): 345-366.

[13] Elton, C.S. (1973): The structure of invertebrate populations inside Neotropical Rain Forest. - Journal of Animal Ecology 42(1):55-104.

[14] Ferreira, R.L., Marques, M.M.G.S.M. (1998): A fauna de artrópodes de serrapilheira de áreas de monocultura com Eucalyptus sp. e mata secundária heterogênea. - Anais da Sociedade Entomológica do Brasil 27(3):395-403.

[15] Fleishman, E., Noss, R.F., Noon, B.R. (2006): Utility and limitations of species richness metrics for conservation planning. - Ecological Indicators 6:543-553.

[16] Gardner, T.A., Barlow, J., Araujo, I.S., Avila-Pires, T.C., Bonaldo, A.B., Costa, J.E., Esposito, M.C., Ferreira, L.V., Hawes, J., Hernandez, M.I.M., et al. (2008): The costeffectiveness of biodiversity surveys in tropical forests. - Ecological Letters 11:139-150.

[17] Gash, J.H.C., Nobre, C.A. (1996): Climatic effects of amazonian deforestation: some results from ABRACOS. - Bulletin of the American Meteorological Society 78:823-830.

[18] Gerlach, J., Samways, M., Pryke, J. 2013. Terrestrial invertebrates as bioindicators: an overview of available taxonomic groups. - Journal of Insect Conservation 17:831-890.

[19] Gollan, J.R., Bruyn, L.L., Reid, N., Smith, D, Wilkie, L. (2011): Can ants be used as ecological indicators of restoration progress in dynamic environments? A case study in a revegetated riparian zone. - Ecological Indicators 11:1517-1525.

[20] Gómez, C., Casellas, D., Oliveras, J., Bas, J.M. (2003): Structure of ground-foraging ant assemblages in relation to land-use change in the northwestern. Biodiversity and Conservation 12:2135-2146.

[21] Hillebrand, H., Bennet, D.M., Cadotte, M.W. (2008): Consequences of dominance: a review of evenness effects on local and regional ecosystem processes. - Ecology 89:1510-1520.

[22] Hoffmann, B.D. (2010): Using ants for rangeland monitoring: Global patterns in the responses of ant communities to grazing. - Ecological Indicators 10:105-111.

[23] Howden, H.F., Nealis, V.G. (1975): Effects of clearing in a tropical rain forest on the composition of the coprophagous scarab beetle fauna (Coleoptera). - Biotropica 7(2):7783.

[24] Knoepp, J.D., Coleman, D.C., Crossley Jr, D.A., Clark, J.S. (2000): Biological indices of soil quality: an ecosystem case study of their use. - Forest Ecology and Management 138:357-368.

[25] Larsen, T.H., Lopera, A., Forsyth, A. (2008): Understanding trait-dependent community disassembly: dung beetles, density functions, and forest fragmentation. - Conservation Biology 22(5):1288-98.

[26] Lavelle, P. (1996): Diversity of Soil Fauna and Ecosystem Function. - Biology International 33:3-16.

[27] Lawton, J. (1999): Are there general laws in ecology? Oikos 84:177-192.

[28] Loyola, R.D, Brito, S-L., Ferreira,R.L. (2006): Ecosystem Disturbances and Diversity Increase: Implications for Invertebrate Conservation. - Biodiversity and Conservation 15:25-42.

[29] Maleque, M.A., Maeto, K., Ishii, H.T. (2009): Arthropods as bioindicators of sustainable forest management, with a focus on plantation forests. - Applied Entomology and Zoology 44(1):1-11.

[30] Mathieu, J., Rossi, J.P., Mora, P., Lavelle, P., Martins, P.F.S., Rouland, C., Grimaldi, M. (2005): Recovery of Soil Macrofauna Communities after Forest Clearance in Eastern Amazonia, Brazil. - Conservation Biology 19:1598-1605. 
[31] McGeoch, M.A., Rensburg B.J., Van Botes, A. (2002): The verification and application of bioindicators: a case study of dung beetles in a savanna ecosystem. - Journal of Applied Ecology 39:661-672.

[32] Nakamura, A., Catterall, C.P., House, A.P.N., Kitching, R.L., Burwell, C.J. (2007): The use of ants and other soil and litter arthropods as bio-indicators of the impacts of rainforest clearing and subsequent land use. - Journal of Insect Conservation 11:177-186.

[33] Oksanen, J., Blanchet, F.G., Kindt, R., Legendre, P., Minchin, P.R., O'Hara, R.B., Simpson, G.L., Solymos, P., Stevens, M.H.H., Wagner, H. (2013): Package " vegan ." - R Packag ver 20: 8:264.

[34] Pianka, E.R. (1983): Evolutionary ecology. - Harper \& Row: New York.

[35] Oliveira-Filho, A.T., Vilela, E.A., Gavilanes, M.L., Carvalho, D.A. (1994): Comparison of the woody flora and soils of six areas of montane semideciduous forest in Southern Minas Gerais, Brazil. - Edinburgh Journal of Botany 51(3):355-389.

[36] R Development Core Team. (2012): R: A language and environment for statistical computing. - R Foundation for Statistical Computing: Vienna. [cited 2012 Jan 20]. Available from http://www.R-project.org>

[37] Ribas, C.R., Campos, R.B.F., Schmidt, F.A., Solar, R.R.C. (2012): Ants as indicators in Brazil: a review with suggestions to improve the use of ants in environmental monitoring programs. - Psyche 20(6):1-23.

[38] Ribas, C.R., Schoereder, J.H., Pic, M., Soares, S.M. (2003): Tree heterogeneity, resource availability, and larger scale processes regulating arboreal ant species richness. - Austral Ecology 28:305-314.

[39] Roberts, D.W. (2013): Package “ labdsv”. - R Package version 16-1: 1-56.

[40] Sala, O.E., Chapin, F.S., Armesto, J.J., Berlow, E., Bloomfield, J., Dirzo, R., HuberSanwald, E., Huenneke, L.F., Jackson, R.B., Kinzig, A.(2000): Global biodiversity scenario for the year 2100. - Science 287:1770-1774.

[41] Schulze, C.H., Waltert, M., Kessler, P.J.A., Pitopang, R., Hahabuddin, Veddeler, D., Muhlenberg, M., Gradstein, R., Leuschner, C., Stephan-Dewenter, I., Tscharntke, T. (2004): Biodiversity indicator groups of tropical land-use systems: comparing plants, birds, and insects. - Ecological Applications 14:1321-1333.

[42] Siemann, E., Tilman, D., Haarstad, J., Ritchie, M. (1998): Experimental tests of the dependence of arthropod diversity on plant diversity. - American Naturalist 152:738-750.

[43] Sobek, S., Steffan-Dewenter, I., Scherber, C., Tscharntke, T. (2009): Spatiotemporal changes of beetle communities across a tree diversity gradient. - Diversity and Distributions 15:660-670.

[44] Solow, A.R. (1993): A simple test for change in community structure. - Journal of Animal Ecology 62(1):191-193.

[45] Suthar, S. (2009): Earthworm communities a bioindicator of arable land management practices: A case study in semiarid region of India. - Ecological Indicators 9:588-594.

[46] Tews, J., Brose, U., Grimm, V., Tielbolger, K., Wichmann, M.C., Schwager, M., Jeltsch, F. (2004): Animal species diversity driven by habitat heterogeneity/ diversity: the importance of keystone structures. - Journal of Biogeography 31:79-92.

[47] Vasconcelos, H.L. (1999): Effects of forest disturbance on the structure of groundforaging ant communities in central Amazonia. - Biodiversity and Conservation 8:409420.

[48] Verdú, J.R., Numa, C., Hernández-Cuba, O. (2011): The influence of landscape structure on ants and dung beetles diversity in a Mediterranean savanna-Forest ecosystem. Ecological Indicators 11:831-839.

[49] Wettstein, W., Schmid, B. (1999): Conservation of arthropod diversity in montane wetlands: effect of altitude, habitat quality and habitat fragmentation on butterflies and grasshoppers. - Journal of Applied Ecology 36:363-373. 